OPEN ACCESS

Edited and reviewed by:

Joshua L. Heazlewood,

University of Melbourne, Australia

*Correspondence:

Liang Chen

liangchen@tricaas.com

${ }^{\dagger}$ These authors have contributed equally to this work.

Specialty section: This article was submitted to Plant Proteomics, a section of the journal

Frontiers in Plant Science

Received: 15 January 2018

Accepted: 29 January 2018

Published: 07 February 2018

Citation:

Xu Y-X, Chen W, Ma C-L, Shen S-Y,

Zhou Y-Y, Zhou L-Q and Chen L (2018) Corrigendum: Proteome and Acetyl-Proteome Profiling of Camellia

sinensis cv. 'Anji Baicha' during

Periodic Albinism Reveals Alterations in Photosynthetic and Secondary Metabolite Biosynthetic Pathways.

Front. Plant Sci. 9:147.

doi: 10.3389/fpls.2018.00147

\section{Corrigendum: Proteome and Acetyl-Proteome Profiling of Camellia sinensis cv. 'Anji Baicha' during Periodic Albinism Reveals Alterations in Photosynthetic and Secondary Metabolite Biosynthetic Pathways}

\author{
Yan-Xia Xu ${ }^{1+}$, Wei Chen ${ }^{1+}$, Chun-Lei Ma ${ }^{1+}$, Si-Yan Shen ${ }^{1}$, Yan-Yan Zhou ${ }^{2}$, Lian-Qi Zhou ${ }^{2}$ \\ and Liang Chen ${ }^{1 *}$
}

${ }^{1}$ Key Laboratory of Tea Biology and Resources Utilization, Ministry of Agriculture, National Center for Tea Improvement, Tea Research Institute of the Chinese Academy of Agricultural Sciences, Hangzhou, China, ${ }^{2}$ Jingjie PTM Biolab (Hangzhou) Co., Ltd., Hangzhou, China

Keywords: acetylation, acetylome, albino, metabolism, PTM, proteomic, tea, overlap

\section{A corrigendum on}

Proteome and Acetyl-Proteome Profiling of Camellia sinensis cv. 'Anji Baicha' during Periodic Albinism Reveals Alterations in Photosynthetic and Secondary Metabolite Biosynthetic Pathways

by Xu, Y.-X., Chen, W., Ma, C.-L., Shen, S.-Y., Zhou, Y.-Y., Zhou, L.-Q., et al. (2017). Front. Plant Sci. 8:2104. doi: 10.3389/fpls.2017.02104

In the original article there was a typographic error with the name of the tea cultivar used in our study.

We incorrectly used "Anjin Baicha" throughout the manuscript; the correct spelling is "Anji Baicha."

The authors apologize for this error and state that this does not change the scientific conclusions of the article in any way.

The original article has been updated.

Conflict of Interest Statement: The authors declare that the research was conducted in the absence of any commercial or financial relationships that could be construed as a potential conflict of interest.

Copyright (c) $2018 \mathrm{Xu}$, Chen, Ma, Shen, Zhou, Zhou and Chen. This is an open-access article distributed under the terms of the Creative Commons Attribution License (CC BY). The use, distribution or reproduction in other forums is permitted, provided the original author(s) and the copyright owner are credited and that the original publication in this journal is cited, in accordance with accepted academic practice. No use, distribution or reproduction is permitted which does not comply with these terms. 